\title{
Spectrin and Other Membrane-Skeletal Components in Human Red Blood Cells of Different Age
}

\author{
Annarita Ciana Cesare Achilli Giampaolo Minetti \\ Università degli Studi di Pavia, Dipartimento di Biologia e Biotecnologie "L. Spallanzani", Laboratori di \\ Biochimica, Pavia, Italy
}

\section{Key Words}

Red blood cell ageing - Protein 4.1 - Ankyrin - Spectrin - p55 - MEMBRANE skeleton • vesiculation • Exosomes • Ectosomes

\begin{abstract}
Background: Old human red blood cells (RBCs) have a reduced surface area with respect to young RBCs. If this decrease occurred through the release of vesicles similar to the spectrinfree vesicles that are shed in vitro under different experimental conditions or during storage, there would be no decrease of membrane-skeleton, but only of lipid bilayer surface area, during RBC ageing in vivo. However, we observed a decrease in spectrin and other membraneskeletal proteins in old RBCs. Because RBCs contain components of the ubiquitin-proteasome system and other hydrolytic systems for protein degradation, we asked whether increased membrane-skeleton fragments could be detected in older RBCs. Methods: Four different anti-spectrin antibodies and an antibody anti-ubiquitin conjugates were used to analyse, by Western blotting, fragments of spectrin and other proteins in RBCs of different age separated in density gradients and characterized for their protein $4.1 \mathrm{a} / 4.1 \mathrm{~b}$ ratio as a cell age parameter. Results: spectrin fragments do exist in RBCs of all ages, they represent a minute fraction of all spectrin, are membrane-bound and not cytoplasmic and do not increase with cell age. Besides spectrin, other membrane-skeletal components decrease with cell age. Conclusion: Observed results challenge the commonly accepted view that decrease in cell membrane throughout $\mathrm{RBC}$ life in vivo occurs via the release of spectrin-free vesicles.

\section{Introduction}

Normal human red blood cells (RBCs) circulate for approximately 120 days and are then cleared in a strictly time-dependent fashion by macrophages, probably in the very same organ, the bone-marrow, from where they originated [1]. When Morrison and coworkers observed that RBC membrane proteins displayed a half-life which was shorter than that of the whole cell, they proposed for the first time that RBCs might lose portions of the membrane during their life in vivo [2]. In subsequent studies it was indeed conformed that the decrease in surface area and in cell volume are two peculiar features of old RBCs in a 


\section{Cellular Physiology Cell Physiol Biochem 2017;42:1139-1152

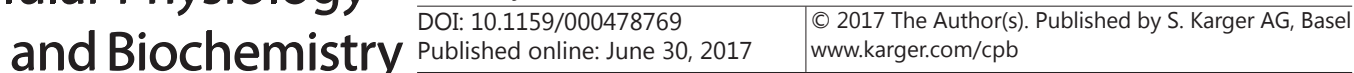 \\ Ciana et al.: Spectrin Fragments in Red Blood Cells of Different Age}

number of mammals. In particular, the oldest circulating RBCs in humans, corresponding to approximately the $1.0 \%$ densest cells, display a surface area that is approximately $17 \%$ lower than that of young RBCs, and a cell volume approximately $25 \%$ lower than that of young cells. The striking result of this balanced decrease is that RBCs maintain throughout their life in the circulation the characteristic shape of a biconcave disk, which is fundamental for conferring to the cell its peculiar deformability [3]. Because at the time of the work of Morrison et al., the study of RBC vesiculation, a common phenomenon that can be induced in vitro by a number of treatments, and that also occurs in RBC storage, was in its infancy, no hypothesis was made about the composition of the membrane that was thought to be lost during RBC ageing in vivo. However, It became soon clear through the study of many, that the micro- and nano-vesicles that are released in vitro under various conditions are devoid of components of the membrane skeleton, so that they were very early qualified as spectrinfree vesicles [4-9]. For this reason, it is now generally accepted that the age-dependent loss of RBC membrane also occurs through the shedding of spectrin-free vesicles.

If this were the case, the area of the lipid bilayer would decrease but not the membrane skeleton, and all the spectrin originally present will be retained in a progressively smaller cell. One natural question was, therefore, whether old RBCs still contain the original endowment of spectrin and other membrane skeletal proteins that was present at the reticulocyte stage [10]. We have recently observed that this is not the case, and that spectrin is subjected to a decrease of approximately the same extent as the decrease in surface area that was described to occur in old RBCs [11]. While holding as true the (undemonstrated) hypotheses that spectrin could not be lost in vivo with supposedly spectrin-free vesicles, we asked whether a process could exist that targets spectrin dimers and/or tetramers for degradation as soon as they dissociate from the portions of lipid bilayer that are lost with the vesicles. One such process is based on the ubiquitin-proteasome system. It could be that the remnants of the degradation process still exist in the circulating RBCs in the form of spectrin fragments (assuming that the degradation process is not so efficient as to degrade the polypeptide into its constituent amino acids) and/or partial adducts of proteins and poly-ubiquitin. To try to answer this question is the purpose of the present work.

\section{Materials and Methods}

\section{RBC purification}

Blood was drawn from healthy human volunteers either from the department staff or from intern students, after informed consent was given for the donation. The blood was freshly collected in VacuTainer tubes with ACD-B as anticoagulant (Vacuette, Greiner Bio-One, Kremsmünster, Austria). RBC purification from leukocytes and platelets was performed by passing blood through a filter composed of $\alpha$-cellulose (cod. C8002, Sigma-Aldrich S.r.l., Milan, Italy) and microcrystalline cellulose (Sigma-Aldrich cod. S5504), mixed in equal parts by weight $[12,13]$. The mixture was suspended in PBS (5 mM sodium phosphate pH 7.4, 154.5 $\mathrm{mM} \mathrm{NaCl}, 4.5 \mathrm{mM} \mathrm{KCl}, 300 \mathrm{mosmol} / \mathrm{kg} \mathrm{H}_{2} \mathrm{O}$ ) supplemented with glucose ( $5 \mathrm{mM}$ final concentration), and poured into the barrel of a $5 \mathrm{ml}$ plastic syringe or a Buchner funnel.

The syringe barrel was used as a filtering device for small volumes of blood (1-1.5 ml): a plug of cotton wool and a filter paper (Whatman $N^{\circ} 4$, cod. 1004-125, GE Healthcare S.r.l., Milan, Italy) septum were inserted at the bottom of the syringe to prevent cellulose from flowing through. For $1 \mathrm{ml}$ of blood, $0.36 \mathrm{~g}$ of cellulose mixture were used. Whole blood was layered on top of the filter. Alternatively, blood was first centrifuged at $1000 \mathrm{~g}$ for $5 \mathrm{~min}$, to separate blood cells from plasma. Plasma was removed and the volume was brought to that of the original blood sample with PBS. In this case the filter was pre-equilibrated with one or two $\mathrm{ml}$ of a 1:10 dilution of autologous plasma in PBS before the cell suspension was layered on the cellulose bed.

For the filtration of larger volumes of blood, plastic Buchner funnels lined with filter paper (Whatman N. 4) were used. For about $10 \mathrm{ml}$ of blood, $6 \mathrm{~g}$ of cellulose mixture were equilibrated in PBS and poured in a $55 \mathrm{~mm}$ internal diameter funnel. Blood was processed as described above and the cell suspension in PBS was carefully layered on the cellulose to minimize disturbance. 


\section{Cellular Physiology Cell Physiol Biochem 2017;42:1139-1152 \begin{tabular}{l|l|l} 
and Biochemistry 10.1159/000478769 & $\begin{array}{l}\text { D) } 2017 \text { The Author(s). Published by S. Karger AG, Basel } \\
\text { www.karger.com/cpb }\end{array}$
\end{tabular} \\ Ciana et al.: Spectrin Fragments in Red Blood Cells of Different Age}

Once the blood completely entered the cellulose bed, PBS was added and the eluate was collected until clear. The eluate contained only RBCs, whereas leukocytes and platelets remained in the filter. Filtered cells were washed three times in PBS before use. The control on the quality of the filtration was carried out by a gelatin zymography protocol especially developed in our lab as described in [13].

\section{Haematocrit measurement}

Haematocrit (Ht) is defined as the volume occupied by RBCs, as percent, with respect to the total volume of a sample of blood or RBC suspension. Two haematocrit capillary tubes per sample were filled with about $60 \mu \mathrm{l}$ of cell suspension, one end was closed with plasticine and the capillary was positioned in the rotor of an ALC4223 micro-haematocrit centrifuge (ALC International, Thermo Fisher Scientific, Milan, Italy). Centrifugation was carried out at $13600 \mathrm{~g}$ for $5 \mathrm{~min}$ at room temperature. The height of the column of packed RBCs and the height of the liquid column in the capillary tubes were then measured with a millimetric ruler. The haematocrit was then calculated as percent ratio between the height of the RBC column and the total height of the liquid in the capillary.

\section{Assay for haemoglobin}

For haemoglobin ( $\mathrm{Hb}$ ) measurement, two aliquots of $25 \mu \mathrm{l}$ of a RBC suspension at $20 \% \mathrm{Ht}$ were diluted in $2.5 \mathrm{ml}$ of Drabkin reagent (Paramedical S.r.l., Salerno, Italia), to convert $\mathrm{Hb}$ to cyanmethaemoglobin. After $10 \mathrm{~min}$ at $25^{\circ} \mathrm{C}$ the cyanmethaemoglobin was quantified by reading the absorbance at $540 \mathrm{~nm}$. The haemoglobin concentration was obtained from the mean value of the two measurements multiplied for the dilution factor in the Drabkin reagent $(2525 / 25=101)$ and for a factor that depends on the standard. The standard (Paramedical S.r.l., Salerno, Italia) was a Hb solution of $20 \mathrm{mg} / 100 \mathrm{ml}$, diluted 1:251 in Drabkin reagent. To calculate the haemoglobin concentration $(\mathrm{g} / \mathrm{ml})$ the absorbance values of the sample had to be multiplied for the factor: $101 \times(20 / 251) \times\left(1 / A_{540}\right.$ Standard $) \times(1 / 100)$. The mean corpuscular haemoglobin concentration (MCHC), expressed as $\mathrm{g} / \mathrm{dl}$ of packed RBCs, was calculated by dividing the $\mathrm{Hb}$ content (g/dl) by the Ht of the RBC suspension, and by multiplying the result by 100 .

\section{Separation of RBCs on discontinuous polyarabinogalactan density gradient}

Preparation of discontinuous density gradients. A concentrated stock solution of polyarabinogalactan was prepared from the purified powder (Larex UF Powder, Larex Inc., St. Paul, MN, USA) following the method of Corash and co-workers [14], with some modifications [15]. This solution was diluted in PBS-G (PBS with $2 \mathrm{mM}$ glucose added) to obtain seven solutions of the following densities: 1.075, 1.090, 1.095, $1.101,1.103,1.110,1.137 \mathrm{~g} / \mathrm{ml}$ respectively. The discontinuous density gradient was prepared by layering the solutions in ultracentrifuge tubes $(16 \times 102 \mathrm{~mm}$ Beckman Ultraclear, Beckman Instruments, Palo Alto, CA, USA) by an automated device developed in our laboratory, equipped with a peristaltic pump. The solutions were poured in the tubes, starting from the densest and ending with the lightest, taking care that the volume occupied by each of the six solutions was approximately the same.

Density separation of RBCs. A RBC suspension at $80 \% \mathrm{Ht}$ was carefully poured on the top of the tubes containing the density gradient ( $2.5 \mathrm{ml}$ for each tube) and centrifuged at $2400 \mathrm{~g}_{\max }$ in a swinging-arm bench centrifuge (ALC PK130, ALC international, Thermo Fisher Scientific, Milan, Italy) equipped with a swingingbucket T535 rotor for 40 min. After centrifugation, RBCs were distributed in six distinct fractions which were all collected by suction with a peristaltic pump. Of the six fractions, fractions $1(\mathrm{~d}=1.075), 3(\mathrm{~d}=$ 1.095) and $6(\mathrm{~d}=1.110)$, as representative of, respectively, young, middle-age and old RBCs, were washed three times in PBS-G and resuspended in PBS-G to obtain $20 \% \mathrm{Ht}$ suspensions. Aliquots of these suspensions were used for subsequent analyses: Hb, Ht, SDS-PAGE, preparation of purified RBC membranes, as described below. Quantification of $\mathrm{Hb}$ in each subpopulation and in the total unfractionated RBC sample was used to calculate the percent of cells recovered in the RBC subpopulations, under the assumption that $\mathrm{Hb}$ content per cell is constant throughout RBC life [16].

Preparation of RBC membranes (ghosts)

Purified (white) RBC membranes (ghosts) were prepared by following the method of Dodge and coworkers [17]. RBCs were first incubated with $5 \mathrm{mM}$ diisopropyl fluorophosphate (DFP), a serine-proteases inhibitor, for $10 \mathrm{~min}$, and subsequently washed three times in PBS. Packed cells were then lysed with 9 volumes of hypotonic buffer ( $5 \mathrm{mM}$ sodium phosphate, $0.5 \mathrm{mM}$ EDTA, $\mathrm{pH} 8.0$ ) at $4{ }^{\circ} \mathrm{C}$. The cell suspension 


\section{Cellular Physiology Cell Physiol Biochem 2017;42:1139-1152 \begin{tabular}{l|l} 
and Biochemistry Published onIIne: June 30, 2017 & $\begin{array}{l}\text { DOI: } 2017 \text { The Author(s). Published by S. Karger AG, Basel } \\
\text { www.karger.com/cpb }\end{array}$
\end{tabular} \\ Ciana et al.: Spectrin Fragments in Red Blood Cells of Different Age}

was shaken and put on ice to keep the temperature close to $4^{\circ} \mathrm{C}$. After $30 \mathrm{~min}$ the lysate was centrifuged at $26000 \mathrm{~g}$ for $30 \mathrm{~min}$ at $4{ }^{\circ} \mathrm{C}$. Supernatant was discharged and the pellet was resuspended with the same buffer and again centrifuged at $26000 \mathrm{~g}$ for $15 \mathrm{~min}$ at $4{ }^{\circ} \mathrm{C}$. The procedure was repeated until white ghost membranes were obtained. Ghosts were resuspended with hypotonic buffer to a final volume equal to that of the initial volume of packed RBCs, resulting in a protein concentration of approximately $5 \mathrm{mg} / \mathrm{ml}$, and dissolved in sample buffer for SDS-PAGE analysis as described below.

\section{Sedimentation of the membrane-skeleton}

A filtered, DFP-treated RBC suspension at 50\% Ht in HNM buffer (5.0 mM HEPES, $150 \mathrm{mM} \mathrm{NaCl}, 4.5$ $\mathrm{mM} \mathrm{KCl}, 2.0 \mathrm{mM} \mathrm{MgCl}_{2}$, pH 7.4) containing $0.5 \mathrm{ml}$ of packed RBCs was mixed with $1.5 \mathrm{ml}$ of $1.67 \%$ Triton $\mathrm{X}-100$ in $\mathrm{HNM}(\mathrm{w} / \mathrm{v})$, so that the final detergent concentration was $1 \%(\mathrm{w} / \mathrm{v})$. The samples were carefully homogenized by tube inversion or, alternatively and purposely, mechanically stressed by repetitive pipetting, to evaluate the effects of handling on the integrity of the membrane-skeleton. Suspensions were incubated on ice for $20 \mathrm{~min}$, transferred to ultracentrifuge tubes $\left(5 \mathrm{ml}\right.$, Ultra-clear ${ }^{\mathrm{TM}}$, code N. 344057, Beckman Coulter S.P.A., Milan, Italy) and centrifuged at $225000 \mathrm{~g}_{\max }$ for $90 \mathrm{~min}$ at $4{ }^{\circ} \mathrm{C}$ in a bench top ultracentrifuge (Optima-Max, equipped with a swinging-arm MLS50 rotor, Beckman Coulter S.P.A., Milan, Italy). After ultracentrifugation three supernatant fractions were collected and the pellet was resuspended in $0.5 \mathrm{ml}$ of HNM buffer. Some experiments were carried out with HKM ( $5 \mathrm{mM}$ HEPES, $150 \mathrm{mM} \mathrm{KCl,} 8 \mathrm{mM} \mathrm{NaCl}, 2$ $\mathrm{mM} \mathrm{MgCl}$, $\mathrm{pH}$ 7.4) instead of HNM, to maintain the physiological $\mathrm{K}^{+}$concentration in the cells, since $\mathrm{K}^{+}$has a role in maintaining the membrane-skeleton integrity; however no significant differences were observed. Proteins of the supernatant fractions and the pellet were analysed by SDS-PAGE as described below.

$\mathrm{Ca}^{2+}$-induced vesiculation of RBCs

RBC vesiculation was induced as described by Allan and Thomas [5]. A DFP-treated RBC suspension at $4 \% \mathrm{Ht}$ (62.5 ml, corresponding to $2.5 \mathrm{ml}$ of packed RBCs) in HNM buffer, supplemented with protease inhibitors (bestatin $20 \mu \mathrm{g} / \mathrm{ml}$, pepstatin $3.5 \mu \mathrm{g} / \mathrm{ml}$, aprotinin $5 \mu \mathrm{g} / \mathrm{ml}$, leupeptin $50 \mu \mathrm{g} / \mathrm{ml}$, final concentrations), was incubated at $37^{\circ} \mathrm{C}$ for 20 min under stirring with a magnetic bar, in the presence of $\mathrm{CaCl}_{2}$ at a final concentration of $0.3 \mathrm{mM}$ (from a $250 \mathrm{mM}$ stock solution in water) and $4 \mu \mathrm{M} \mathrm{Ca}^{2+}$-ionophore A23187 (from a $10 \mathrm{mM}$ stock solution in DMSO). Aliquots $(250 \mu \mathrm{l})$ of the suspension were collected before and after incubation and centrifuged. From the supernatant, $200 \mu \mathrm{l}$ were removed and the cells resuspended in the remaining buffer, to give a suspension of $20 \% \mathrm{Ht}$ for subsequent SDS-PAGE analysis. After collection of the end point aliquot, EGTA was added to the suspension to give a final concentration of $2 \mathrm{mM}$, from a $60 \mathrm{mM}$ stock solution in water, pH 7.0, and RBCs were pelleted by centrifugation at $1000 \mathrm{~g}$ for $5 \mathrm{~min}$ at $15{ }^{\circ} \mathrm{C}$. The vesicle-containing supernatant was collected and centrifuged at $27000 \mathrm{~g}$ for $20 \mathrm{~min}$ at $15{ }^{\circ} \mathrm{C}$, then the supernatant was discarded and the vesicles in the pellet were resuspended in $1200 \mu \mathrm{l}$ of HNM buffer, transferred to two $1.5 \mathrm{ml}$ Eppendorf tubes (600 $\mu \mathrm{l}$ each), mixed with $400 \mu \mathrm{l}$ of isotonic Percoll ${ }^{\mathrm{TM}}$ (GE Healthcare S.r.l., Milan, Italy) (prepared by adding $731 \mathrm{mg} \mathrm{NaCl}$ to $100 \mathrm{ml}$ Percoll ${ }^{\mathrm{TM}}$ ) and centrifuged at $35000 \mathrm{~g}$ for $15 \mathrm{~min}$ at $15{ }^{\circ} \mathrm{C}$ to generate a self-forming Percoll ${ }^{\mathrm{TM}}$ gradient into which residual RBCs and cell fragments could be separated from vesicles. After centrifugation, vesicles floating in the middle of the gradient were collected and washed in HNM by centrifugation at $35000 \mathrm{~g}$ for $30 \mathrm{~min}$ at $15^{\circ} \mathrm{C}$. Vesicles were resuspended in $400 \mu \mathrm{l}$ of $\mathrm{HNM}$ buffer and centrifuged at $18000 \mathrm{~g}$ for $15 \mathrm{~min}$ at $15{ }^{\circ} \mathrm{C}$, in order to pellet possible residues of Percoll ${ }^{\mathrm{TM}}$. Vesicles were then transferred to new $1.5 \mathrm{ml}$ tubes and processed for SDSPAGE as described below.

Polyacrylamide gel electrophoresis in sodium dodecyl sulfate (SDS-PAGE)

Samples were analysed by SDS-PAGE following the Laemmli method [18]. Ghosts, vesicles, supernatant fractions and pellet obtained from the sedimentation of the membrane-skeleton, were mixed with 0.5 volumes of 3X sample buffer for SDS-PAGE [50 mM Tris/HCl, pH 6.8, 5\% SDS (w/v), 0.01\% bromophenol blue (w/v), 35\% sucrose (w/v), 5 mM EDTA, 200 mM DTT], while whole RBC samples (as 20\% Ht suspensions in the appropriate buffer) were dissolved with 9 volumes of "dilute SDS-PAGE sample buffer" [obtained by mixing one volume of 3X SDS-PAGE sample buffer with 1.7 volumes of 5\% (w/v) SDS in water]. This is necessary to maintain the optimal SDS/protein ratio, considering the high amount of $\mathrm{Hb}$ present in whole RBCs. Samples were then heated for $15 \mathrm{~min}$ at $60{ }^{\circ} \mathrm{C}$. Proteins were separated on $7 \%(\mathrm{w} / \mathrm{v}$ ) acrylamide isocratic gels for protein $4.1 \mathrm{a}$ and $4.1 \mathrm{~b}$ quantification or $5-15 \%(\mathrm{w} / \mathrm{v})$ acrylamide linear gradient gels for the 
Table 1. Primary and secondary antibodies used for Western blotting in the study. The dilution factors used for preparing the working solution from the commercial concentrated solution are reported in parentheses

\begin{tabular}{ll}
\multicolumn{1}{c}{ Primary Antibodies } & \multicolumn{1}{c}{ Secondary Antibodies } \\
\hline Anti human $\alpha$-spectrin, mouse monoclonal (IID2), & HRP-conjugated goat anti-mouse IgGs, \\
SCBT sc-53900 $(1: 1000)$. & Bio-Rad 170-6516 $(1: 10000)$ \\
Anti human $\alpha$-spectrin, mouse monoclonal (B-12), & HRP-conjugated goat anti-mouse IgGs, \\
SCBT sc-271130 $(1: 1000)$. & Bio-Rad 170-6516 $(1: 10000)$ \\
Anti human $\beta$-spectrin, mouse monoclonal (VD4), & HRP-conjugated goat anti-mouse IgGs, \\
SCBT sc-53901 $(1: 2000)$ & Bio-Rad 170-6516 $(1: 10000)$ \\
Anti human $\beta$-spectrin, mouse monoclonal (B-1), & HRP-conjugated goat anti-mouse IgGs, \\
SCBT sc-374309 $(1: 1000)$ & Bio-Rad 170-6516 $(1: 10000)$ \\
Anti human protein 4.1, mouse polyclonal, Abnova & HRP-conjugated goat anti-mouse IgGs, \\
H00002035-A01 $(1: 2000)$ & Bio-Rad 170-6516 $(1: 4000)$ \\
Anti human p55, goat polyclonal (N-19), & HRP-conjugated mouse anti-goat IgGs, \\
SCBT sc-13490 $(1: 200)$ & SCBT sc-2354(1:4000) \\
Anti human glycophorin C, mouse monoclonal (BRIC10), & HRP-conjugated goat anti-mouse IgGs, \\
SCBT sc-59183 $(1: 10000)$ & Bio-Rad 170-6516 $(1: 10000)$ \\
Anti human band 3, mouse monoclonal (BIII-136), & HRP-conjugated goat anti-mouse IgGs, \\
Sigma-Aldrich B9277 (1:15000) & Bio-Rad 170-6516 $(1: 15000)$ \\
Anti mono-/ poly-ubiquitin, mouse monoclonal (FK2), & HRP-conjugated goat anti-mouse IgGs, \\
Life Sensors Inc. AB120 (1:1000) & Bio-Rad 170-6516 (1:4000) \\
\hline
\end{tabular}

Western blotting. The reason for not running isocratic gels, but gradient gels for Western blotting was that the electro-transfer of proteins from the upper (cathodic) region of discontinuous gels to Western blotting membranes is notoriously inefficient. In gradient gels, the transfer of high molecular weight proteins improves because they migrate to lower regions of the gels comparted to isocratic gels. SDS-PAGE was performed in an electrophoretic chamber (MINI-PROTEAN III from Bio-Rad) filled with running buffer [25 mM Tris, $192 \mathrm{mM}$ glycine, 0.1\% SDS (w/v), pH 8.3]. Electrophoresis was carried out by applying a constant voltage of $100 \mathrm{~V}$ until samples were well packed in the stacking gel. Then the voltage was maintained at $150 \mathrm{~V}$ until the end of the run (approximately $2 \mathrm{~h}$ ). Gels were then subjected to Western blotting and chemiluminescence detection for the immunodetection of a given protein or, alternatively, they were stained with $0.2 \%(\mathrm{w} / \mathrm{v}$ ) Coomassie brilliant blue R-250 in 20\% (w/v) trichloroacetic acid for 30 min and destained with $7.5 \%(\mathrm{v} / \mathrm{v})$ acetic acid, for direct visualization of all protein bands.

\section{Western blotting and immunodetection}

Proteins separated by SDS-PAGE were electrotransferred from the gel to a PVDF (polyvinylidene fluoride) membrane, by using a commercial Mini-Trans-Blot apparatus (Bio-Rad Laboratories S.r.l., Milan, Italy), in the following buffer solution: $20 \mathrm{mM}$ Tris, $150 \mathrm{mM}$ glycine, $20 \%$ methanol (v/v) pH 8.3, at a constant current of $200 \mathrm{~mA}$ for $2 \mathrm{~h}$. Once transferred to PVDF, the separated proteins were detected with specific antibodies. The membrane was first incubated for $1 \mathrm{~h}$ in a blocking solution [5\% non-fat dry milk in $10 \mathrm{mM}$ Tris/HCl pH 7.5, $100 \mathrm{mM} \mathrm{NaCl}, 0.1 \%$ Tween 20 (v/v)]. The membrane was then incubated overnight at $4{ }^{\circ} \mathrm{C}$ with the primary antibody directed against the protein of interest. Antibodies were diluted to the appropriate titre (see Table 1) in washing buffer [50 mM Tris/ $\mathrm{HCl} \mathrm{pH} \mathrm{7.5,0.2} \mathrm{M} \mathrm{NaCl,} 1 \mathrm{~g} / \mathrm{l}$ polyethylene glycol (PEG) 20000, $0.5 \mathrm{ml} / \mathrm{l}$ Tween-20, $1 \mathrm{~g} / \mathrm{l} \mathrm{BSA}$ ] and the solution was supplemented with $0.2 \%(\mathrm{w} / \mathrm{v}$ ) $\mathrm{NaN}_{3}$ as a preservative, so that it could be used multiple times. The membrane was then washed 8 times (8 min each) in washing buffer and incubated for $1 \mathrm{~h}$ at $25^{\circ} \mathrm{C}$ under gentle rocking with a solution containing the horseradish (HRP)-conjugated secondary antibody (see Table 1). The antibodies used in the studies were from: Santa Cruz Biotechnology (SCBT), Dallas, TX, USA; Sigma-Aldrich S.r.l., Milan, Italy; Bio- Rad Laboratories S.r.l., Milan, Italy; LifeSensors, Inc., Malvern, PA, USA; Abnova, Taipei, Taiwan). The PVDF membrane was then washed 6 times ( 5 min each) with washing buffer, and immunodetection was carried out with the chemiluminescence kit ECL Prime Western Blotting Detection Reagent (GE Healthcare S.r.l., Milan, Italy) according to the manufacturer's instructions. The light emission was detected by a digital image acquisition system: Molecular Imager ChemiDoc XRS (Bio- Rad Laboratories S.r.l., Milan, Italy).

\section{Results}

RBCs contain spectrin fragments

Young, middle-aged and old RBCs were obtained as populations of RBCs of, respectively, $1.075 \mathrm{~g} / \mathrm{ml}, 1.095 \mathrm{~g} / \mathrm{ml}$ and $1.110 \mathrm{~g} / \mathrm{ml}$ buoyant densities after separation of freshly drawn blood on discontinuous gradients of polyarabinogalactan. The RBC fractions of different age were characterized for cell recovery, MCHC and the cell-age parameter protein $4.1 \mathrm{a} / 4.1 \mathrm{~b}$ 


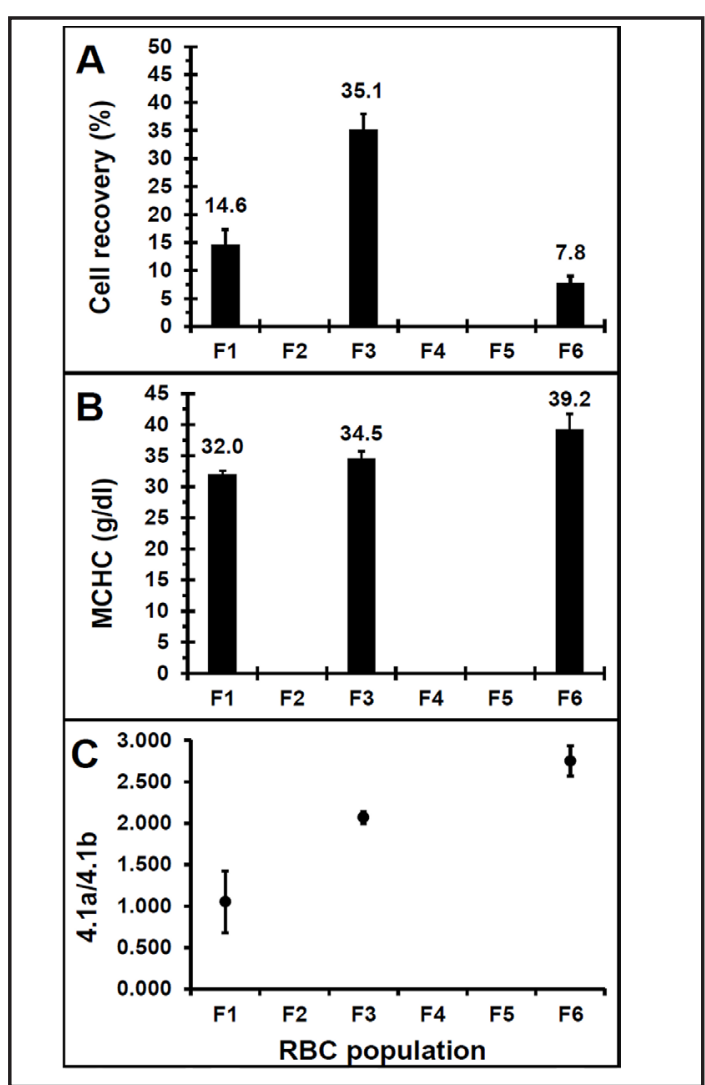

Fig. 1. RBCs from 4 different donors were separated into six different fractions of different cell density/ age by centrifugation in discontinuous polyarabinogalactan density gradients. Fractions $1(\mathrm{~d}=1.075$ $\mathrm{g} / \mathrm{ml}), 3(\mathrm{~d}=1.095 \mathrm{~g} / \mathrm{ml})$ and $6(\mathrm{~d}=1.110 \mathrm{~g} / \mathrm{ml})$ were further characterized as representative of, respectively, young, middle-aged and old RBCs. A) The percentage of cells in each fraction was evaluated by percent fraction of $\mathrm{Hb}$ contained in it with respect to the total population of cells loaded in the gradient. B) MCHC, in $\mathrm{g} / \mathrm{dl}$ of packed RBCs, was calculated as described under Materials and Methods. C) The $4.1 \mathrm{a} / 4.1 \mathrm{~b}$ ratio of the three subpopulations of RBCs was determined by running ghosts obtained from an aliquot of RBCs in 7\% polyacrylamide gels that were stained with Coomassie brilliant blue and subject to acquisition with a scanner as specified elsewhere [15]. Error bars represent the standard deviation.

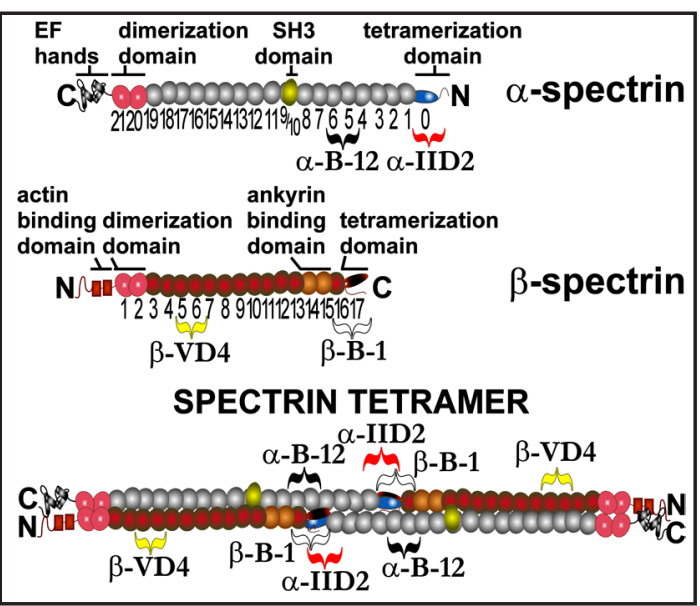

Fig. 2. Schematic view of $\alpha$ - and $\beta$-spectrin molecules represented as isolated monomers (top and middle) and as a tetramer, which is believed to be the structural and functional basic unit into which spectrin is organized in the membrane-skeleton under physiological conditions. The polypeptide in both $\alpha$ - and $\beta$-spectrin is for the most part folded into multiple characteristic motifs of approximately 106 amino acids each, organized in three antiparallel coiled-coiled segments of $\alpha$-helix joined by short loops. Whereas $\alpha$-spectrin contains 20 full repeats and one partial repeat, with only one $\alpha$-helical strand, at the $\mathrm{N}$-terminus, $\beta$-spectrin contains 16 full 3-helix bundles and a partial one, with two only strands of $\alpha$-helix at the C-terminus. Other important domains in the spectrin monomers are indicated and include the dimerization domains existing in both $\alpha$ - and $\beta$-spectrin, the actin-binding domain, the ankyrin binding domain and the tetramerization domain. One $\alpha$ - and one $\beta$-spectrin monomers form a heterodimer characterized by a low dissociation constant. Two heterodimers join head-to-head to form the heterotetramer shown at the bottom. The regions where the four antibodies used in this study bind on the spectrin molecules are also shown. Redrawn from [36].

(which increases with increasing cell age), as shown in Fig. 1. The RBCs of different age were subjected, as whole cells, to SDS-PAGE and Western blotting with four different antibodies, two directed against $\alpha$-spectrin and two against $\beta$-spectrin epitopes. Antibodies against $\alpha$-spectrin were IID2 and B-12, that bind respectively to the N-terminus and to an epitope between repeats 5 and 6; antibodies against $\beta$-spectrin were VD4 and B-1, which recognize repeats 5-6 and the C-terminus of the $\beta$-spectrin polypeptide chain (Fig. 2).

The results obtained for $\alpha$-spectrin showed that with both antibodies a series of fragments (besides the full length polypeptide) were visible (Fig. 3A and 3B). Fragments 


\section{Cellular Physiology Cell Physiol Biochem 2017;42:1139-1152 and Biochemistry Published $\begin{aligned} & \text { DOI: 10.1159/000478769 } \\ & \text { (c) } 2017 \text { The Author(s). Published by S. Karger AG, Basel } \\ & \text { www.karger.com/cpb }\end{aligned}$

Fig. 3. Immunodetection of $\alpha$ - spectrin, $\beta$-spectrin and their fragments in whole RBCs. Young $(\mathrm{Y})$, middle-aged (M) and old (O) RBCs obtained from four different separation experiments (Exp 1-4) were analysed by SDS-PAGE and Western blotting, using four different monoclonal antibodies directed against epitopes in $\alpha$-spectrin (A and B) and $\beta$-spectrin (C and $D)$. The samples were loaded to have the equivalent of $5 \times 10^{6}$ whole RBCs per lane in all blots except the one with anti $\beta$-spectrin VD4, where $2.5 \times 10^{6}$ whole RBCs per lane were loaded (D). T is a sample of the total population of RBCs before density fractionation. Below each Western blot, the approximate binding site for the respective antibody in the spectrin tetramer is shown.

visualized with IID2 antibody were mostly at the same molecular masses as those detected by B-12, in a range from $80 \mathrm{kDa}$ to $250 \mathrm{kDa}$. For $\beta$-spectrin, antibodies revealed that also fragments of this polypeptide were present in whole RBCs (Fig. 3C and 3D). In this case the fragments detected by the two

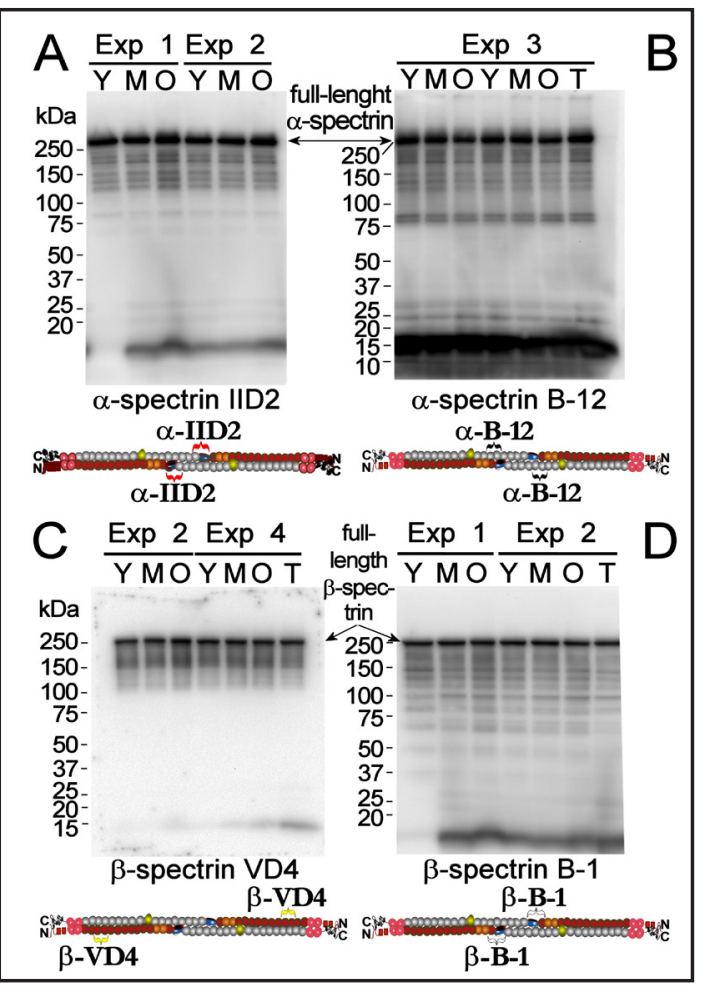
antibodies were similar only in the range from 150 to $200 \mathrm{kDa}$; VD4 antibody recognized a few other fragments, until about $100 \mathrm{kDa}$, whereas B-1 antibody recognized fragments also of molecular masses down to 20-25 kDa.

From the obtained results it was only possible to conclude that fragments of both $\alpha$ and $\beta$-spectrin were detectable in RBCs of all ages, but that no differences in the amounts of spectrin fragments were observed among young, middle-aged and old RBCs.

With all antibodies, a signal, that appeared to increase, sporadically, in old RBCs, was present at molecular masses around $30 \mathrm{kDa}$. This, however, had to be interpreted as an artifact associated with single haemoglobin subunits joined together (non-covalently or covalently, but in the latter case not through disulfide bonds) to form dimers, trimers or tetramers of apparent molecular masses of respectively 32,48 and $64 \mathrm{kDa}$, and become visible because they develop a chemiluminescence signal owing to a pseudo-peroxidase activity of haemecontaining proteins.

The amounts of fragments above $75 \mathrm{kDa}$ seemed to slightly increase from young to old RBCs in some experiments; however the method is not suitable for a precise quantitative analysis, despite its high sensitivity, in particular on those fragments which are not clearly defined.

Considering $\alpha$-spectrin, the majority of the fragments were recognized by both antibodies and had a molecular mass lower, but near the mass of the entire protein, suggesting that some $\alpha$-spectrin was degraded starting from the C-terminus (Fig. 3A and 3B). The B-12 antibody recognized also fragments of lower molecular mass than those detected by IID2. This could be explained by imaging that part of $\alpha$-spectrin breakdown took place, at a certain time, from the N-terminus. Again, the lack of a major trend to increase in the amount of such fragments in older RBCs did not allow to consider spectrin fragmentation as a marker of RBC senescence.

The fragments of $\beta$-Spectrin showed similar but mirrored results. With $\beta$-spectrin VD4 antibody (Fig. 3C), which recognizes an epitope near the N-terminus of the protein, fewer fragments were detected than with B-1 antibody (Fig. 3D), which recognizes the C-terminus, a result compatible with the fragmentation process beginning from the $\mathrm{N}$-terminus of $\beta$-spectrin. 
Fig. 4. Sedimentation of RBC membraneskeletons. RBCs were incubated with $1 \%$ (v/v) Triton X-100 at $4{ }^{\circ} \mathrm{C}$ for $20 \mathrm{~min}$, and subsequently ultracentrifuged (See also Materials and Methods). Three supernatant fractions (collected from the top of the tube and numbered accordingly 1, 2, 3, of volumes as indicated under "fract. vol." - named "soluble") and the pellet of membrane-skeletons (P), plus a sample of whole RBCs (T) were analysed by SDS-PAGE and Western blotting, with anti $\beta$-spectrin antibody (VD4). For whole RBC samples, loading was performed in terms of $\mu \mathrm{l}$ of equivalent packed RBCs. The pellet, resuspended in HNM buffer

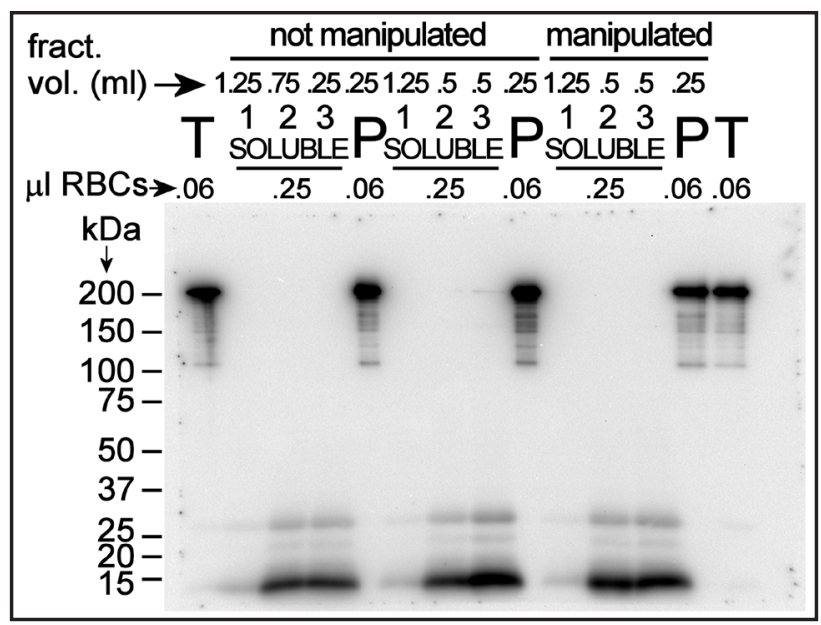
to have the same initial volume of the packed RBCs from which it was obtained, was loaded to have the same amount of membrane/membrane-skeleton components, present in the equivalent amount of packed RBCs. The three supernatant fractions were loaded to have the same amounts of cytoplasmic content of the equivalent volume of packed RBCs. Similar results were obtained in two other experiments with blood from different donors.

\section{Sedimentation of the RBC membrane-skeleton}

Since the fragments from both $\alpha$ - and $\beta$-spectrin were detected in samples of whole RBCs, nothing could be concluded about their subcellular localizations, whether it was cytosolic or in the membrane. To answer this question, a careful separation of the cytosolic compartment from the membrane/membrane-skeleton was performed.

RBCs were treated with a non-ionic detergent (Triton X-100) and subsequently ultracentrifuged, to sediment the membrane-skeleton together with residual components of the lipid bilayer and integral membrane proteins (membrane rafts, see below). Some samples were subjected to mechanical stress by pipetting, in order to evaluate if manipulation could increase the amount of fragments possibly released into the soluble fraction. After sedimentation three supernatant fractions (called "soluble" and corresponding to the soluble fraction, comprising the cytosol and those lipids and integral membrane proteins that were solubilized by the detergent) and the pellet (membrane-skeleton) were collected from each sample, and analysed by Western blotting. The soluble fractions were loaded in excess, four times the amount loaded for the membrane-skeleton, because we expected that the fragments, if present in the cytosol, would be highly diluted and difficult to detect.

Surprisingly, the results clearly showed that the soluble fraction did not contain any fragments, as they were all present in the membrane-skeleton pellet, together with the intact spectrin molecules (Fig. 4). The manipulated samples showed no differences with respect to the non-manipulated ones.

\section{Identification of spectrin fragments in $R B C$ ghosts}

The experiments with the isolated membrane skeletons were carried out starting with whole RBCs and under isotonic conditions. We asked whether the same spectrin fragments that were observed in intact cells were also present in RBC ghosts. The results show that fragments from both $\alpha$ - and $\beta$-spectrin were present in ghosts; however, when compared with those detected in whole RBCs, some differences in the type of fragments were observed (Fig. 5).

Whole RBCs contained fragments of $\alpha$ - and $\beta$-spectrin, detected, respectively, by the IID2 and VD4 antibodies, in a range from 100 to $250 \mathrm{kDa}$, which were detected also in ghosts but in lower amounts (Fig. 5A and 5C). The B-12 anti $\alpha$-spectrin antibody recognized, in whole RBCs, fragments with molecular masses between 75 and $100 \mathrm{kDa}$, which were not visible in ghosts, even when ghosts were overloaded ( $1 \mu \mathrm{l}$ of equivalent packed cells) (Fig. $5 \mathrm{~B})$. The analysis of $\beta$-spectrin fragments with B-1 antibody revealed similar fragments in

\section{KARGER}




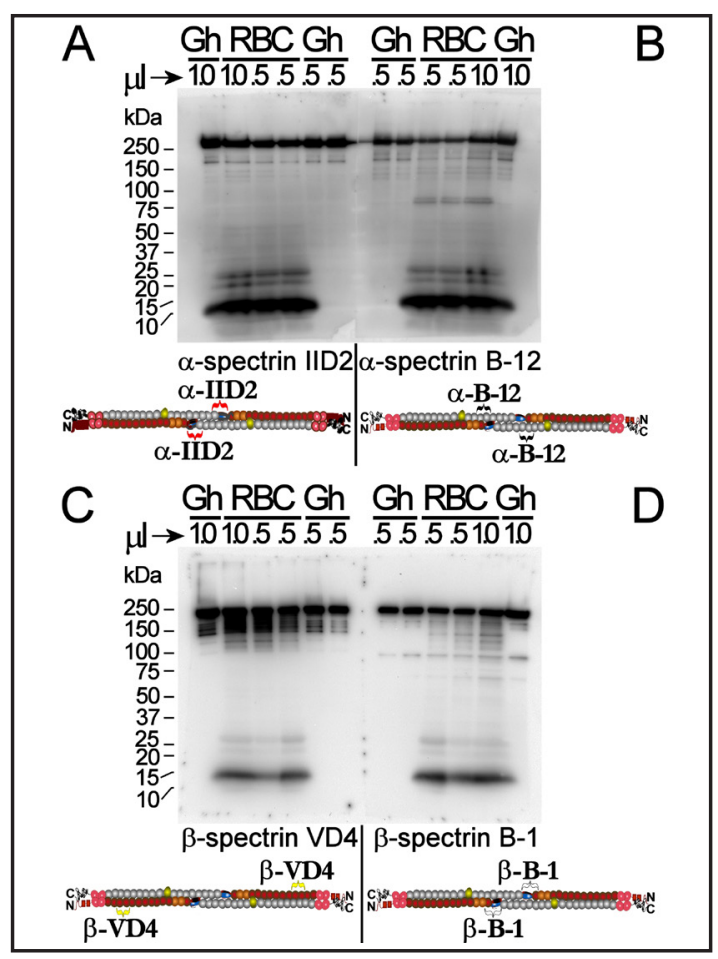

Fig. 5. Immunodetection of $\alpha$-spectrin, $\beta$-spectrin and their fragments in RBC ghosts. Ghosts were subjected to SDS-PAGE and Western blotting, using two antibodies against $\alpha$-spectrin (A and B) and two antibodies against $\beta$-spectrin (C and D). RBCs from the same donor were used as control. Loading was performed in terms of $\mu \mathrm{l}$ of packed RBCs or equivalent packed ghosts, as indicated at the upper end of the membranes. The blots shown are from one experiment representative of three other experiments carried out with blood from different donors.

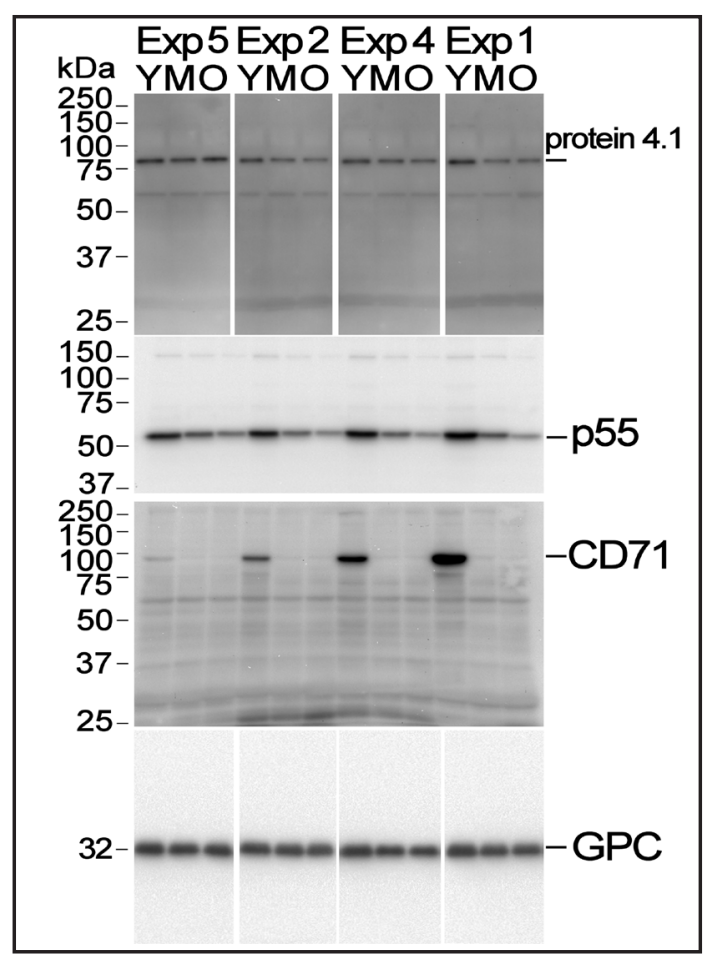

Fig. 6. Immunodetection of protein 4.1, p55 and glycophorin C (GPC) in whole RBCs of different age from 4 different donors (Exp. 1, Exp. 2, Exp. 4, Exp. 5). The contribution of reticulocytes to the signal displayed by young RBCs is visible in the Western blotting of CD71 (the transferrin receptor, which is lost with reticulocyte maturation). In each lane, approximately $1.25 \times 10^{6}$ RBCs were loaded for protein 4.1 and GPC and $7.5 \times 10^{6}$ RBCs for CD71 and p55 Western blotting.

whole cells and ghosts between 150 and $250 \mathrm{kDa}$. Fragments with lower masses appeared to be absent in ghosts, with the exception of a band of about $100 \mathrm{kDa}$ (Fig. 5D). The presence of fragments in ghosts was analysed also in ghosts prepared from RBCs of different ages: as for the whole cells, there were no significant differences between ghosts from young, middleaged and old RBCs (not shown).

Other components of the membrane skeleton in RBCs of different age

In order to verify whether the decrease in spectrin was paralleled by the decrease in other components of the membrane skeleton, Western blottings of protein 4.1 and of protein p55 were carried out by loading identical numbers of whole RBCs of different age. Results are shown in Fig. 6 where it is possible to verify that both p55 and protein 4.1 decrease from young to old RBCs. A Western blotting of glycophorin C, the transmembrane protein to which the spectrin skeleton is anchored through protein 4.1 and p55 is also shown, to highlight the parallel decline in the peripheral and in the integral components of the membrane.

Vesicles produced in vitro contain spectrin fragments

RBCs of different ages seemed to contain the same type of fragments, with more fragments in whole cells as compared to ghosts. Since there was no increase in the amount of fragments from young to old RBCs, it could be argued that the fragments produced 
Fig. 7. Immunodetection of $\alpha$ - spectrin, $\beta$-spectrin and their fragments in vesicles. Vesicle release by RBCs was induced by treatment with $\mathrm{Ca}^{2+}$-ionophore A23187 in the presence of $\mathrm{Ca}^{2+}$, as described in Materials and Methods. Control cells (C), $\mathrm{Ca}^{2+}-$ treated cells (Ca) and vesicles (Ves) were analysed by SDS-PAGE and Western blotting, using the anti-spectrin antibodies already described above. The membranes were re-decorated with anti-band 3 antibody and the blots are shown below the corresponding anti-spectrin blots (except for anti- $\beta$-spectrin B1 antibody were the blot was damaged). For control and $\mathrm{Ca}^{2+}$-treated cells loading was performed in terms of $\mu$ l of packed RBCs. For vesicles, different quantities of suspension were loaded so that the amount of vesicle membrane exceeded the amount of membrane from cells, as demonstrated by the higher amount of band 3 in vesicles samples visible in the anti-band 3 blots. The blots shown are from one experiment representative of three with similar results.

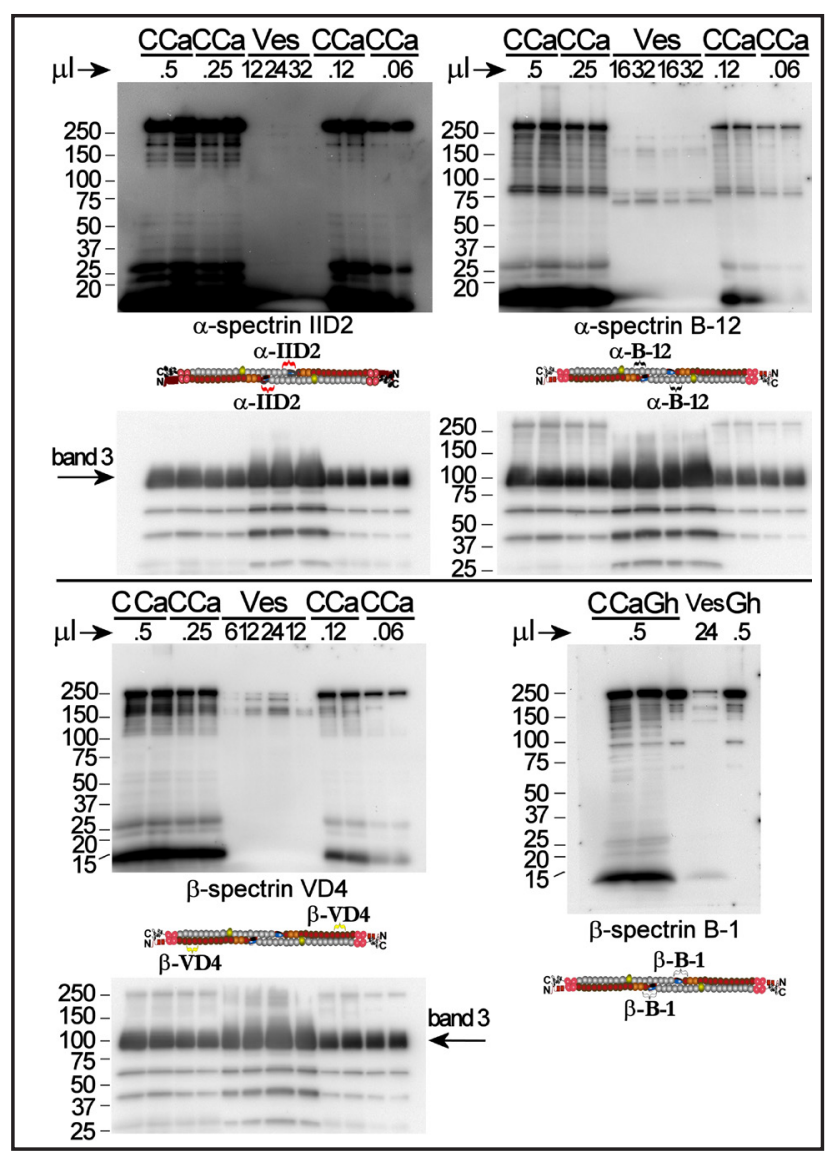

Fig. 8. Immunodetection of ubiquitin-conjugates in RBC of different ages. Young (Y), middle-aged (M) and old (O) RBCs were analysed as whole RBCs (A) and ghosts (B) by SDS-PAGE and Western blotting, using a primary antibody against both mono- and polyubiquitinated proteins. The samples were loaded to have $5 \times 10^{6}$ RBCs (A) and $5 \times 10^{6}$ RBC ghosts (B) per lane. The Western blots shown are from one experiment representative of three carried out with blood from different donors and displaying similar results.

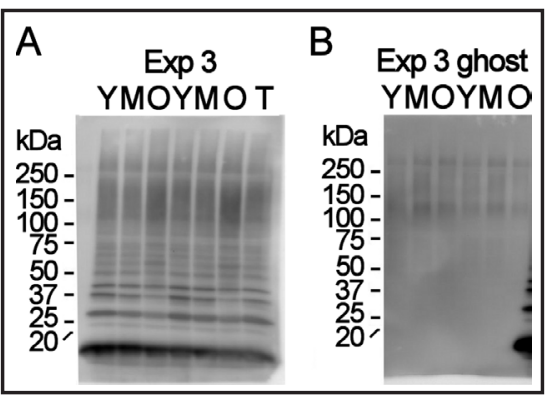

during ageing did not accumulate but were rather completely degraded or, alternatively, removed from the cells by an unknown mechanism. It has been proposed that during their ageing in vivo RBCs decrease in size by losing membrane in the form of vesicles. Since our observations suggested that fragments may remain bound to the membrane, we decided to analyse if vesicles obtained in vitro by incubating $\mathrm{RBCs}$ with $\mathrm{Ca}^{2+}$ and $\mathrm{Ca}^{2+}$-ionophore (A23187) contained any kind of spectrin fragments.

Results showed that a few fragments of both $\alpha$ - and $\beta$-spectrin were present in vesicles, although they did not seem to be the fragments as those found in cells (Fig. 7). Moreover, no visible differences were found between $\mathrm{Ca}^{2+}$-treated and control cells. The possibility that the detected fragments were present because of contamination by cells was ruled out by loading the samples so that the amount of membrane in vesicles exceeded the amount of membrane in cells, on the basis of their band 3 content. Thanks to this expedient, if the fragments detected were due to contamination by cells, we would have also had a high amount of spectrin in the vesicles samples. In addition, it seemed unlikely that fragments derived from cell contamination because these were of different molecular mass in cells as compared to vesicles. 


\section{Cellular Physiology Cell Physiol Biochem 2017;42:1139-1152 \\ \begin{tabular}{l|l} 
DOI: 10.1159/000478769 & O 2017 The Author(s). Published by S. Karger AG, Basel \\
www.karger.com/cpb
\end{tabular} \\ Ciana et al.: Spectrin Fragments in Red Blood Cells of Different Age}

\section{Identification of ubiquitin-conjugates in RBCs of different ages}

Recent proteomic studies have identified components of the ubiquitin conjugative system (ubiquitin-activating enzymes E1 and E2, ubiquitin ligase E3) and proteasome subunits in mature human RBCs [19-22]. Ubiquitin-conjugates were already detected in rabbit reticulocytes, and in lower amount also in RBCs of the same species [23]. Therefore, we analysed RBCs of different age for the possible presence of ubiquitin-conjugated proteins. The result of a representative Western blotting where young, middle-aged and old RBCs were analysed, as whole cells and as ghosts, with an antibody which recognizes both monoand poly-ubiquitinated proteins (but not free ubiquitin) is shown in Fig. 8. The distribution of conjugate bands in whole RBCs of different age is qualitatively similar; however, some differences in their amounts can be appreciated. A more intense signal is present, in old $\mathrm{RBCs}$, in the range from 75 to $250 \mathrm{kDa}$, while the signal below $75 \mathrm{kDa}$ presents a more variable distribution, with some bands more intense in the young with respect to the old RBCs. In the analysis of RBC ghosts obtained from the same fractions, although the signal level was generally lower, the banding pattern resembled that of the whole cells.

\section{Discussion}

Spectrin is synthesized early during erythroid development $[24,25]$ and it appears to be progressively assembled at the membrane into its characteristic supramolecular structure in a process which is coordinated by the availability of anchoring sites in the membrane, in the form of band 3 and glycophorin $C$ molecules. At this earlier stage, excess spectrin may undergo selective degradation to keep the required balance [25] with the cognate ligands at the membrane. From now on, with the enucleation step and the maturation of the reticulocyte, it seems that the process is so constructed as to spare all the spectrin molecules, because they have all been accommodated at the membrane [26]. This well-regulated selfassembly appears to have as the final result that an exactly balanced amount of membrane skeleton will be assembled for the bilayer it will be required to support, with no excess or defect of either of the components. In this paper we asked if is there was any remodeling of the spectrin skeleton during the ageing in vivo of RBCs, under the hypotheses that if they released spectrin-free vesicles as a basic mechanism to decrease in surface area, this would automatically result in an excess of spectrin within the cell. What we actually found is that apparently such an imbalance never arises during RBC life in the circulation, as not only the cell loses membrane surface area, but also spectrin and other components of the membrane skeleton [11]. To account for the spectrin decline we wondered whether this could be achieved through proteolysis and investigated whether vestiges of such process could exist in the form of spectrin fragments in the RBCs of progressively older age. Results revealed that spectrin fragments do exist in RBCs but they do not appear to change quantitatively during RBC ageing. Taken together, results concerning fragments of $\alpha$-spectrin and $\beta$-spectrin were consistent with a scenario whereby proteolysis affected spectrin dimers beginning from the "tail" of the dimer (by convention the region with the C-terminus of $\alpha$-spectrin and the $\mathrm{N}$-terminus of $\beta$-spectrin, see Fig. 1). This would also imply that proteolysis could start when spectrin is present in the tetrameric form, disengaged from the junctional complex, and thus exposing one or two tails of the tetramer. Looking at the structure of the spectrin dimer these results suggest an initial loss of the dimerization domain, which is positioned in the repeats 20-21 of $\alpha$-spectrin ( $\mathrm{C}$-terminus) and repeats $1-2$ of $\beta$-spectrin ( $\mathrm{N}$-terminus) (Fig. 1). Proteolysis could then proceed until both the polypeptide chains are fully degraded to their constituent amino-acids that are no longer detectable by immunoblotting. We don't know whether the unchanging amounts of spectrin fragments detected in RBCs of all ages was the result of a stationary equilibrium between formation and degradation, or the observed fragments were a subpopulation of spectrin by-products that for some reasons (denaturation, aggregation, precipitation), resisted further degradation during the final maturational steps in the erythropoietic process. According to earlier studies a process where spectrin monomers undergo degradation seems to occur in an earlier developmental phase of the 


\section{Cellular Physiology Cell Physiol Biochem 2017;42:1139-1152 \\ \begin{tabular}{ll|l} 
and Biochemistry Published onIIne: June 30, 2017 & $\begin{array}{l}\text { (c) 2017 The Author(s). Published by S. Karger AG, Basel } \\
\text { www.karger.com/cpb }\end{array}$ \\
\hline
\end{tabular} \\ Ciana et al.: Spectrin Fragments in Red Blood Cells of Different Age}

erythroblast soon after the spectrin is synthesized. Our spectrin fragments as seen in mature RBCs should then be interpreted as vestiges of this early maturational degradation of some excess spectrin [25].

The Triton X-100 fractionation study revealed that it was possible to clearly separate the membrane skeleton from the solubilized bilayer and that all the spectrin fragments were tightly anchored to the Triton X-100-insoluble fraction. This was corroborated by the result obtained with samples that were mechanically stressed to verify whether the fragments were or not only loosely attached to the skeleton. This indicated that the binding affinity of the fragments was at least as high as that of the molecular interactions that exist between the various components of the membrane skeleton, that are known to be particularly resistant to shearing, at least under isotonic conditions [27]. However, that at least some of the fragments were more loosely bound came from the observation that some of the lower molecular weight forms were not detected when ghost membranes were analysed (Fig. 5) as if they were more easily detached under the conditions of hypotonicity and shear that are adopted for ghost preparation. If it is excluded that the fragments were denatured forms of spectrin that simply precipitated in the membrane, it may be hypothesized that they were still bound to the skeleton in proximity of the junctional complex, because they retained at least one functional actin-binding domain.

The membrane-skeleton pellets ("Triton shells") that were obtained by treating whole RBCs with 1\% Triton X100 have been thoroughly characterized as being composed of not only the spectrin skeleton plus the transmembrane proteins through which it is anchored to the lipid bilayer (and of all the accessory proteins of the junctional complexes), but also of a lipid component [28] to be later identified as the Detergent-Resistant-Membrane (DRM), or membrane rafts, which remain associated with the spectrin skeleton under these conditions, and require an increase in $\mathrm{pH}$ and ionic strength of the medium to be released [29-32]. It could be therefore that the spectrin fragments were associated with the DRM component of the Triton shells. We have not examined the DRMs for the presence of spectrin and spectrin fragments in this study, so we cannot exclude that they might be at least partially localized in these microdomains.

The results of the vesiculation study also seemed to indicate that spectrin fragments were associated with the membrane skeleton, as the vast majority of them was retained in the parent cell, whereas the spectrin-free vesicles were also largely free of spectrin fragments, although they contained small amounts of them, mostly different from the ones found in the cell. Also the origin of the latter remains to be established, and whether they were produced during the vesiculation process, for instance by $\mathrm{Ca}^{2+}$-dependent proteolysis (although a broad range of protease inhibitors was used in our vesiculation experiments).

The analysis of ubiquitin conjugates in RBCs of different age showed immunoreactive material as a diffuse band above $100 \mathrm{kDa}$ that seemed to increase with RBC age and a number of discrete bands that appeared to decrease with increasing RBC age. If the signal was really due to poly-ubiquitynated proteins remains to be established. A role for the ubiquitinproteasome system was proposed for the "remodelling" of the membrane-skeleton during the maturation from reticulocytes to RBCs, in fact spectrin appears to be synthesized in excess and the molecules that have not taken their place in the organized membrane-skeleton will have to be degraded. In chicken RBCs, the excess of $\beta$-spectrin was proven to be degraded in an ATP-dependent manner, further suggesting a possible implication of this pathway in the proteolysis of this protein [25], but at earlier stages during erythroblast development.

According to most recent and reliable proteomic studies, RBCs appear to contain components of both the ubiquitine-ligase system and of the proteasome [21], but whether they are functional is questionable [33]. It could be that some ubiquitin E3 ligase activity was still present as a vestige and active on some proteins, but the very fact that such signal increased in older RBCs proved that the proteasome, if present at all, was non-functioning. Its characteristic "processivity" would have resulted in the complete proteolysis of the target proteins down to the individual amino acids. 


\section{Cellular Physiology Cell Physiol Biochem 2017;42:1139-1152 \begin{tabular}{l|l} 
and Biochemistry Published 10.1159/000478769 217 & $\begin{array}{l}\text { (c) 2017 The Author(s). Published by S. Karger AG, Basel } \\
\text { www.karger.com/cpb }\end{array}$ \\
\hline
\end{tabular} \\ Ciana et al.: Spectrin Fragments in Red Blood Cells of Different Age}

At any rate, it would be arbitrary to exclude now that the decline in spectrin from young to old RBCs could be due to extensive proteolysis via one or more of the proteolytic pathways that exist in mature RBCs, from the proteasome-based [33] to calpain- [34] or, perhaps, caspase-dependent [35]. Future work will be aimed at comparing the pattern of spectrin fragments observed here to the pattern of fragments obtained by limited proteolysis of RBC ghosts with the above-mentioned proteolytic activities.

In summary, we have documented here that spectrin and other components of the membrane skeleton decrease with RBC age, a counterintuitive notion if it is assumed that $\mathrm{RBC}$ lose membrane during their in vivo ageing by shedding spectrin-free vesicles as they commonly do when stimulated in vitro by a variety of experimental manoeuvres. The fact that no increase in free spectrin monomers or dimers (dissociated from the membrane skeleton) or in their fragments was observed during RBC ageing, strongly indicate that RBCs might lose a balanced portion of lipid bilayer and membrane-skeleton as they age in vivo. Because RBCs do not appear to be spontaneously able to perform this function in vitro, this process may require the active intervention of the spleen and the reticulo-endothelial system to occur.

\section{Acknowledgments}

The work was partly funded by the Fondazione Cariplo, Milan, Italy, project 2011-2099, to GM, and it was in part conducted under the project RELEVANCE (Regulation of red cell life-span, erythropoiesis, survival, senescence and clearance, N. 675115) of the Horizon 2020 Marie Skłodowska-Curie Actions Innovative Training Networks of the European Commission.

\section{Disclosure Statement}

The work presented in this article is original and is not under consideration for publication in another journal. All the authors have contributed actively to the study and the writing of the manuscript. The authors declare that they do not have any conflict of interest.

\section{References}

1 Clark MR: Senescence of red blood cells: progress and problems. Physiol Rev 1988;68:503-554.

2 Morrison M, Michaels AW, Phillips DR, Choi SI: Life span of erythrocyte membrane protein. Nature 1974;248:763-764.

-3 Waugh RE, Narla M, Jackson CW, Mueller TJ, Suzuki T, Dale GL: Rheologic properties of senescent erythrocytes: loss of surface area and volume with red blood cell age. Blood 1992;79:1351-1358.

-4 Lutz HU, Liu SC and Palek J: Release of spectrin-free vesicles from human erythrocytes during ATP depletion. I. Characterization of spectrin-free vesicles. J. Cell Biol 73;1977:548-560.

5 Allan D, Thomas P: $\mathrm{Ca}^{2+}$-induced biochemical changes in human erythrocytes and their relation to microvesiculation. Biochem J 1981;198:433-440.

6 Wagner GM, Chiu DT, Yee MC, Lubin BH: Red cell vesiculation--a common membrane physiologic event. J Lab Clin Med 1986;108:315-324.

7 Iida K, Whitlow MB, Nussenzweig V: Membrane vesiculation protects erythrocytes from destruction by complement. J Immunol 1991;147:2638-2642.

8 Greenwalt TJ: The how and why of exocytic vesicles. Transfusion 2006;46:143-152.

-9 Nguyen DB, Ly TB, Wesseling MC, Hittinger M, Torge A, Devitt A, Perrie Y, Bernhardt I: Characterization of Microvesicles Released from Human Red Blood Cells. Cell Physiol Biochem 2016;38:1085-1099.

-10 Zweig SE, Tokuyasu KT, Singer SJ: Member-associated changes during erythropoiesis. On the mechanism of maturation of reticulocytes to erythrocytes. J Supramol Struct Cell Biochem 1981;17:163-181.

11 Ciana A, Achilli C, Gaur A, Minetti G: Membrane remodelling and vesicle formation during ageing of human red blood cells. Cell Physiol Biochem 2017;42:1127-1138. 


\section{Cellular Physiology Cell Physiol Biochem 2017;42:1139-1152 \begin{tabular}{l|l} 
and Biochemistry Publisher 10.1159/000478769 & $\begin{array}{l}\text { (c) } 2017 \text { The Author(s). Published by S. Karger AG, Basel } \\
\text { www.karger.com/cpb }\end{array}$
\end{tabular} \\ Ciana et al.: Spectrin Fragments in Red Blood Cells of Different Age}

12 Beutler E, West C, Blume KG: The removal of leukocytes and platelets from whole blood. J Lab Clin Med 1976;88:328-333.

13 Achilli C, Ciana A, Balduini C, Risso A, Minetti G: Application of gelatin zymography for evaluating low levels of contaminating neutrophils in red blood cell samples. Anal Biochem 2011;409:296-297.

14 Corash LM, Piomelli S, Chen HC, Seaman C, Gross E: Separation of erythrocytes according to their age on a simplified density gradient. J Lab Clin Med 1974;84:147-151.

15 Arduini A, Minetti G, Ciana A, Seppi C, Brovelli A, Profumo A, Vercellati C, Zappa M, Zanella A, Dottori S, Bonomini M: Cellular properties of human erythrocytes preserved in saline-adenine-glucose-mannitol in the presence of L-carnitine. Am J Hematol 2007;82:31-40.

-16 Mosca A, Paleari R, Modenese A, Rossini S, Parma R, Rocco C, Russo V, Caramenti G, Paderi ML, Galanello R: Clinical utility of fractionating erythrocytes into "Percoll" density gradients. Adv Exp Med Biol 1991;307: 227-238.

17 Dodge JT, Mitchell C, Hanahan DJ: The preparation and chemical characteristics of haemoglobin-free ghosts of human erythrocytes. Arch Biochem Biophys 1963;100:119-130.

18 Laemmli UK: Cleavage of structural proteins during the assembly of the head of bacteriophage T4. Nature 1970;15:680-685.

19 Low TY, Seow TK, Chung MCM: Separation of human erythrocyte membrane associated proteins with onedimensional and two-dimensional gel electrophoresis followed by identification with matrix assisted laser desorption/ionization-time of flight mass spectrometry. Proteomics 2002;2:1229-1239.

20 Kakhniashvili DG, Bulla LA Jr, Goodman SR: The human erythrocyte proteome: analysis by ion trap mass spectrometry. Mol Cell Proteomics 2004;3:501-509.

21 Pasini EM, Kirkegaard M, Mortensen P, Lutz HU, Thomas AW, Mann M: In-depth analysis of the membrane and cytosolic proteome of red blood cells. Blood 2006;108:791-801.

22 Lange PF, Huesgen PF, Nguyen K, Overall CM: Annotating N-termini for the human proteome project: $\mathrm{N}$-termini and $\mathrm{N} \alpha$-acetylation status differentiate stable cleaved protein species from degradation remnants in the human erythrocyte proteome. J Proteome Res 2014; 13:2028-2044.

23 Haas AL: Ubiquitin-mediated processes in erythroid cell maturation. In: Red blood cell aging. Plenum Press, New York, (1991) pp. 191-205.

24 Chang H, Langer PJ, Lodish HF: Asynchronous synthesis of erythrocyte membrane proteins. Proc Natl Acad Sci USA 1976;73:3206-3210.

25 Woods CM, Lazarides E: Degradation of unassembled alpha- and beta-spectrin by distinct intracellular pathways: regulation of spectrin topogenesis by beta-spectrin degradation. Cell 1985;40:959-969.

26 Geiduschek JB, Singer SJ: Molecular changes in the membranes of mouse erythroid cells accompanying differentiation. Cell 1979;16:149-163.

27 Lange Y, Hadesman RA, Steck TL: Role of the reticulum in the stability and shape of the isolated human erythrocyte membrane. J Cell Biol 1982;92:714-721.

28 Yu J, Fischman DA, Steck TL: Selective solubilization of proteins and phospholipids from red blood cell membranes by nonionic detergents. J Supramol Struct 1973;1:233-248.

29 Ciana A, Balduini C, Minetti G: Detergent-resistant membranes in human erythrocytes and their connection to the membrane-skeleton. J Biosci 2005;30:317-328.

30 Ciana A, Achilli C, Balduini C, Minetti G: On the association of lipid rafts to the spectrin skeleton in human erythrocytes. Biochim Biophys Acta 2011;1808:183-190.

-31 Ciana A, Achilli C, Hannoush RN, Risso A, Balduini C, Minetti G: Freely turning over palmitate in erythrocyte membrane proteins is not responsible for the anchoring of lipid rafts to the spectrin skeleton: a study with bio-orthogonal chemical probes. Biochim Biophys Acta 2013;1828:924-931.

- 32 Ciana A, Achilli C, Minetti G: Membrane rafts of the human red blood cell. Mol Membr Biol 2014;31:47-57.

33 Neelam S, Kakhniashvili DG, Wilkens S, Levene SD, Goodman SR: Functional 20S proteasomes in mature human red blood cells. Exp Biol Med 2011;236:580-591.

34 Damonte G, Guida L, Sdraffa A, Benatti U, Melloni E, Forteleoni G, Meloni T, Carafoli E, De Flora A: Mechanisms of perturbation of erythrocyte calcium homeostasis in favism. Cell Calcium 1992;13:649-658.

-35 Lang E, Lang F: Mechanisms and pathophysiological significance of eryptosis, the suicidal erythrocyte death. Semin Cell Dev Biol 2015;39:35-42.

-36 Ipsaro JJ, Harper SL, Messick TE, Marmorstein R, Mondragón A, Speicher DW: Crystal structure and functional interpretation of the erythrocyte spectrin tetramerization domain complex. Blood 2010;115:4843-4852. 